\title{
Compras públicas sustentáveis: um estudo de caso sobre a relevância da construção de guia prático específico
}

\section{Lucas Ribeiro Ferraz ${ }^{1}$ e Daniel Ribeiro de Oliveira ${ }^{2}$}

${ }^{1}$ Instituto Federal de Educação, Ciência e Tecnologia do Rio de Janeiro. Rua Sebastião Lacerda, S/N. Centro. Paracambi-RJ, Brasil (CEP 26600-000). E-mail: lucas.ferraz@ifrj.edu.br.

${ }^{2}$ Universidade Federal Rural do Rio de Janeiro. Rodovia BR 465, km 07, S/N. Zona Rural. Seropédica-RJ, Brasil (CEP 23890-000).

Resumo. A preocupação com a preservação ambiental tem ganhado relevância na agenda de debates internacionais. Destarte, a implementação de políticas públicas voltadas ao fomento do ecodesenvolvimento vêm sendo cada vez mais valorizadas, buscando-se garantir o bem-estar das atuais e futuras gerações. Neste sentido, as compras públicas sustentáveis despontam como instrumento de incentivo e orientação do mercado. A pesquisa realizou um estudo de caso no Campus Paracambi, do Instituto Federal de Educação, Ciência e Tecnologia do Rio de Janeiro, tendo como objetivo verificar a necessidade de criação de ferramenta voltada à orientação e fomento das licitações sustentáveis. Os métodos utilizados foram a pesquisa bibliográfica e documental, aliada à aplicação de roteiros de questionário e entrevista aos atores envolvidos nas etapas iniciais do processo de aquisição. Como resultado, a investigação observou dificuldades que comprometem a efetivação das compras sustentáveis no campus estudado, destacando-se a insegurança dos profissionais envolvidos na instrução processual, em especial devido à insuficiência de capacitação, à cultura organizacional resistente a mudanças e ao desconhecimento de instrumentos de apoio específico. Portanto, inferiu-se a importância da construção de guia prático orientado aos gestores e servidores solicitantes, focado na elaboração de requisições com critérios sustentáveis.

Palavras-chave: Licitação sustentável; Especificação do objeto; Desenvolvimento sustentável.

Abstract. Sustainable public purchases: $A$ case study on the relevance of the construction of a specific practical guide. The concern with environmental preservation has gained relevance in the international debate agenda. Thus, the implementation of a public policies aimed at promoting eco-development has been increasingly valued, seeking to ensure the well-being of current and future generations. In this sense, sustainable public
Recebido

$23 / 03 / 2020$

Aceito

$12 / 04 / 2020$

Disponível on line $13 / 04 / 2020$

Publicado

$30 / 04 / 2020$

Acesso aberto

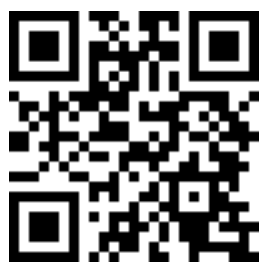

ORCID

(D) 0000-0002-6350-4690 Lucas Ribeiro Ferraz

(1) 0000-0002-8787-8320

Daniel Ribeiro de

Oliveira

ISSN 2359-1412/RBGAS-2020-0048/2020/7/15/10/123

Rev. Bras. Gest. Amb. Sustent.

http://revista.ecogestaobrasil.net 
procurement emerges as an instrument of incentive and market orientation. The research carried out a case study on the Paracambi campus of the Federal Institute of Education, Science and Technology of Rio de Janeiro, with the objective of verifying the need to create a tool aimed at orienting and promoting sustainable bidding. The methods used were bibliographic and documentary research, combined with the application of questionnaire scripts and interviews with the actors involved in the initial stages of the acquisition process. As a result, the investigation observed difficulties that compromise the realization of sustainable biddings on the studied campus, highlighting the insecurity of the professionals involved in the procedural instruction, especially due to the insufficiency of training, the organizational culture resistant to changes and the lack of specific support instruments. Therefore, it was inferred the importance of building a practical guide for managers and requesting employees, focused on the preparation of requisitions with sustainable criteria.

Keywords: Sustainable bidding; Object specification; Sustainable development.

\section{Introdução}

Os temas relacionados ao desenvolvimento sustentável têm ganhando cada vez mais notoriedade no debate público mundial, questionando-se os níveis de consumo assistidos e discutindo-se possíveis soluções para a degradação ambiental (Laloe, 2014).

Neste cenário, a redução do impacto das atividades humanas e uso racional das matérias-primas são considerados como formas de conservar os recursos hídricos, a produção de alimentos, a atmosfera e outros aspectos essenciais à manutenção da qualidade de vida. 0 desafio de conciliar as necessidades da sociedade contemporânea com a preservação do planeta para as futuras gerações é o ponto central da discussão, visto a importância de buscar o equilíbrio entre as dimensões econômica, social e ambiental. Com estas três áreas formando o chamado tripé da sustentabilidade (Betiol et al., 2012).

As compras públicas constituem significativa parcela do Produto Interno Bruto (PIB) brasileiro, somente em 2019, o Poder Executivo Federal homologou mais de 48 bilhões de reais em suas contratações, segundo o site Portal de Compras do Governo Federal (Brasil, 2020). Logo, observa-se a capacidade de influência dos órgãos governamentais nas tendências de mercado. Neste contexto, o Estado pode atuar como importante agente de transformação dos atuais parâmetros de produção e consumo, estimulando a competitividade e inovação dos fornecedores por meio da criação de demanda (Couto e Coelho, 2015).

As compras públicas sustentáveis (CPS), que, segundo Biderman et al. (2008), também podem ser denominadas por compras verdes, compras ambientalmente amigáveis, ecoaquisições, licitações positivas e licitações sustentáveis, surgem como instrumento do Poder público para impulsionar o mercado na direção da sustentabilidade, tendo em vista, o montante financeiro gerado pelas suas contratações (Oliveira e Santos, 2015).

O Instituto Federal de Educação, Ciência e Tecnologia do Rio de Janeiro (IFRJ) é uma autarquia federal especializada na oferta de educação profissional e tecnológica, 
estruturada na forma multicampi e com sua Reitoria sediada na cidade do Rio de Janeiro. É uma instituição pertencente a administração indireta da União, logo sujeito as obrigações referentes às pessoas jurídicas de direito público, dentre elas, a exigência de realização de processo licitatório para assegurar a legalidade das suas aquisições.

Como um órgão público, o IFRJ também deve adotar políticas voltadas ao desenvolvimento nacional sustentável, assim fazendo uso do seu poder de compra para estimular o mercado neste sentido. Dada a sua natureza voltada ao ensino, pesquisa e extensão a instituição tem obrigação acentuada na promoção da aprendizagem dos seus alunos, servidores, colaboradores e da comunidade.

Couto e Coelho (2015) apontam as CPS como um assunto que ainda desperta dúvidas em gestores, pregoeiros e servidores solicitantes de materiais, obras e serviços, dada a dificuldade encontrada em adotar critérios sustentáveis nos itens requeridos nos processos. Os mesmos autores, alertam que o problema pode estar relacionado a cultura organizacional, capacitação insuficiente, processo decisório, dentre outros fatores. Desta forma, o artigo se justifica por trazer contribuições teóricas e práticas, tendo em vista a incipiente produção científica na área e a baixa efetividade das licitações positivas como mandamento legal e demanda social.

A presente publicação é parte da pesquisa de programa de mestrado, estando orientada a superação das barreiras encontradas na implementação das compras sustentáveis, como prática regular nas licitações do campus estudado. Como objetivo, o artigo busca verificar a necessidade de criação de ferramenta específica direcionada ao auxílio de gestores e solicitantes de materiais. Isto, por meio da condução de estudo de caso aplicado a análise das experiências, concepções e dificuldades enfrentadas por esses servidores nas etapas iniciais dos processos de ecoaquisição.

A delimitação conceitual da pesquisa é pautada no entendimento das licitações sustentáveis como importante instrumento para o desenvolvimento nacional, assim buscando equilibrar os interesses econômicos, sociais e ambientais. Como delimitação geográfica tem-se o Campus Paracambi do IFRJ, sendo a investigação focada, especialmente, nos atores envolvidos nos processos de compras, em documentos públicos e produções bibliográficas.

\section{Compras públicas sustentáveis}

A licitação é um procedimento formal realizado pelos órgãos da Administração Pública Direta e Indireta, sendo destinada a compra de materiais, contratação de obras e serviços, alienações, permissões, concessões e locações de bens móveis e imóveis, conforme previsto na Lei no 8.666/1993 (Brasil, 1993). Diferentemente dos entes privados, os públicos necessitam seguir rigorosos trâmites para a execução de suas aquisições e desfazimentos, com as regulamentações estando expressa em diversos dispositivos legais (Mello, 2015; Meirelles, 2016).

Meirelles (2016, p. 310) define a licitação como instrumento pelo qual "Administração Pública seleciona a proposta mais vantajosa para o contrato de seu interesse, inclusive o da promoção do desenvolvimento econômico sustentável e fortalecimento de cadeias produtivas de bens e serviços domésticos". O processo licitatório se constitui em procedimento administrativo prévio a efetivação da contratação, celebrando o ajuste de vontades entre o ente público e o licitante, em estrita conformidade com os princípios básicos que regem as compras públicas (Mello, 2015; Di Pietro, 2016).

Inserido no contexto global de preocupação com os atuais níveis de produção e consumo e seu impacto no ecossistema, inicialmente as licitações verdes no Brasil foram pautadas na atenção a aspectos ecológicos, visto que o legislador prevê medidas voltadas, especialmente, a redução da pressão das atividades humanas sobre os recursos naturais (Biderman et al., 2008). 
Betiol et al. (2012), Silva e Barki (2012) e Laloe (2014) afirmam que a Administração, além dos cuidados ambientais, também deverá ter atenção aos custos sociais e econômicos advindos da aquisição de bens e serviços que causam maior impacto, sejam nas etapas de produção, utilização e descarte. Ainda segundo os autores, as licitações positivas proporcionam a redução de gastos ao priorizarem a duração e eficiência superiores dos objetos contratados, que no curto e médio prazo, implicam em economia e benefícios a sociedade.

Desta forma, após a alteração e regulamentação do artigo 3ํㅜㄹ da Lei no 8.666/1993 (Brasil, 1993), a seleção da proposta mais vantajosa para a administração passou a ter novo significado, ou seja, a busca do interesse público precisa estar compatibilizada com as práticas sustentáveis. Logo, os aspectos ambientais, econômicos e sociais precisam ser considerados no planejamento das licitações (Di Pietro, 2016).

A licitação sustentável fundamenta-se na ideia de pensar além da aplicação imediata do recurso público, pois os custos das aquisições englobam além dos valores pagos no momento da contratação, visto a necessidade de avaliar toda a cadeia produtiva e o ciclo de vida do bem/serviço, ou seja, considerar a fabricação, a utilização e o descarte. Portanto, para atingir o interesse público, o gestor também precisa ponderar os benefícios mediatos das aquisições, pensando no melhor para toda a sociedade (Biderman et al., 2008; Alencastro et al., 2014).

Autores como Biderman et al. (2008), Caldas e Nonato (2013), Oliveira e Santos (2015), Laloe (2014) e Di Pietro (2016) apontam a importância do Estado como agente transformador das atuais relações de produção e consumo, com vistas ao desenvolvimento mais sustentável. A possibilidade de se efetivar políticas públicas orientadas neste sentido decorre, especialmente, do poder regulatório, de fomento e econômico exercido pelos órgãos governamentais.

Em linhas gerais, o poder regulatório permite a emissão de normas que incentivem as empresas a aumentar a responsabilidade socioambiental e punam aquelas que não estão adotando tal prática. A capacidade de fomento está relacionada ao estímulo à pesquisa e inovação de novas técnicas produtivas, assim buscando a redução dos impactos causados pelas atividades humanas a partir da otimização na fabricação de bens e na execução de obras e serviços. No aspecto econômico ressalta-se a capacidade de criação de demanda por meio das CPS, visto o elevado valor das contratações governamentais (Oliveira e Santos, 2015).

Betiol et al. (2012) afirma que a preocupação com a sustentabilidade não está mais ligada somente a grupos ambientalistas, pois o conceito vem se permeando em considerável parcela da sociedade. Desta forma, as empresas têm moldado a estratégia de negócios para aproveitar a vantagem competitiva proporcionada pelo estímulo à inovação, redução de custos e, consequente, valorização da marca.

Destarte, com o uso das CPS, pode-se agir estrategicamente no fomento do desenvolvimento sustentável por meio das especificações de produtos e/ou serviços que consideram, ao menos, as consequências ambientais, sociais e econômicas (Caldas e Nonato, 2013). Assim, favorecendo o uso de materiais renováveis, métodos de fabricação e produção sustentáveis, logística reversa, manutenção, reuso, reciclagem, entre outras ações que englobam todo o ciclo de vida do material/serviço (Silva e Barki, 2012).

\section{Especificação sustentável do objeto}

A necessidade da inclusão de critérios sustentáveis nas contratações públicas trouxe mudanças de paradigmas nas licitações brasileiras, pois a administração recebeu a incumbência de fomentar o desenvolvimento nacional sustentável, também, a partir das suas compras. Neste sentido, o gestor público que outrora apenas buscava a proposta mais vantajosa, em geral, a partir do "menor preço" da aquisição, agora deve incorporar 
critérios e práticas visando o equilíbrio entre os aspectos ambientais, sociais e econômicas nos instrumentos convocatórios (Alencastro et al., 2014; Di Pietro, 2016).

A especificação do objeto é uma das etapas iniciais do processo de contratação, pois é o momento onde a Administração delineia as descrições dos bens, serviços e obras que deseja contratar. Este procedimento é regulamentado em diversas normas que versam sobre as compras públicas. Refere-se a instante crucial do processo de contratação, dado que o detalhamento impreciso do objeto a ser licitado, seja por falta ou excesso de informações, pode comprometer a qualidade do produto adquirido, o valor final da compra, a competitividade do certame ou até mesmo inviabilizá-lo (Di Pietro, 2016).

Sabendo que o Edital ou a Carta-convite deve conter as informações do certame e compreendendo os objetivos das compras públicas. Temos que os critérios e práticas de sustentabilidade, estabelecidos pela Administração, devem estar contidos no instrumento convocatório a fim de publicizar as condições de celebração e execução do contrato (Di Pietro, 2016).

Alencastro et al. (2014) e Laloe (2014) observam que a legislação e a jurisprudência brasileira, especialmente após 2010, têm valorizado a realização das CPS. Assim, a administração precisa considerar métodos mais ecoeficientes na instrução dos processos de aquisição, ponderando as etapas de extração, fabricação, utilização e descarte dos produtos e matérias-primas.

Neste sentido, Betiol et al. (2012, p. 28) aponta que os "sistemas de rotulagem estão cada vez mais presentes no mercado para diferenciar empresas, processos e produtos que adotam voluntariamente determinados princípios e normas, dentro de padrões reconhecidos nacional e/ou internacionalmente". Ainda segundo a autora, as empresas que ostentam os selos ambientais em seus produtos agregam valor as suas marcas, justamente por demonstrar aos consumidores atenção a critérios e práticas sustentáveis.

O Catálogo de Materiais (CATMAT), do Sistema Integrado de Administração de Serviços Gerais (SIASG), do Ministério do Planejamento, Desenvolvimento e Gestão (MPDG) é um banco digital, periodicamente revisado e atualizado, acessado a partir do site ComprasNet (Brasil, 2014). Com o advento do CATMAT, o Poder Público pôde padronizar as descrições dos bens adquiridos e atribuir códigos de referência, facilitando o acesso às especificações usualmente utilizadas e o controle dos itens comprados, assim tornando os procedimentos licitatórios mais céleres (Alencastro et al., 2014).

O Catálogo de Materiais contém exemplos de especificações (com e sem critérios sustentáveis) de materiais, sendo apresentado como uma relação dos objetos contratáveis para a execução das atividades fins e meios da administração pública. Trata-se de rol exemplificativo, pois o CATMAT admite a inclusão de novos itens, unidades de fornecimento e descrições não constantes no cadastro, isto mediante solicitação da Unidade Gestora, segundo procedimento regulado em manual (Brasil, 2014).

Alencastro et al. (2014) argumentam que o cadastro de itens tem sido uma problemática recorrente no processo de compras públicas, dada a dificuldade apresentada pelos atores envolvidos e a pouca variedade de produtos elencados como sustentáveis no catálogo. Assim, sinalizando a necessidade de capacitação de solicitantes, pregoeiros e gestores nas operações desenvolvidas no CATMAT, a fim de ampliar a diversificação dos materiais disponibilizados.

Por fim, compreende-se as licitações como importantes instrumentos de promoção do desenvolvimento nacional sustentável, visto a possibilidade de englobar aspectos relacionados aos meios econômico, político, social, ambiental e cultural. Mas, o estabelecimento destes critérios nos instrumentos convocatórios deve ser realizado com 
bastante cuidado pela Administração, buscando aliar as especificações disponíveis no CATMAT, pesquisar os selos ambientais admitidos nas jurisprudências, cooperar com outros órgãos governamentais e preservar a isonomia e competitividade nos certames (Couto e Ribeiro, 2016).

\section{Metodologia}

A pesquisa possui características que a define como predominantemente de natureza qualitativa, possuindo orientação epistemológica interpretativa. A modalidade de pesquisa utilizada é o estudo de caso segundo os preceitos de Yin (2001).

0 viés qualitativo é indicado para se obter informações, documentos e elementos decorrente das interações humanas e de processos dinâmicos, não realizáveis por meio de instrumentos estatísticos, também sendo apropriada à construção de planos voltados a melhoria de programas ou rotinas em execução (Vergara, 2005).

0 estudo de caso foi precedido de pesquisas bibliográfica e documental para fundamentação teórica e levantamento de informações relevantes ao trabalho. Para a coleta de dados foram utilizadas o exame documental, a aplicação de questionários semiabertos e a condução de entrevista semiestruturada. No tratamento e interpretação das informações obtidas, utilizou-se o método de análise de conteúdo conforme disciplinado por Bardin (2016).

Destarte, foi realizado um estudo de caso no Campus Paracambi do IFRJ focado nos servidores solicitantes e gestores, ou seja, nos atores envolvidos na fase inicial do processo de compra.

A análise documental foi realizada a partir da investigação em documentos escritos disponíveis na forma eletrônica, todos de fontes de arquivos públicos. Os documentos estudados foram obtidos por meio da consulta aos seguintes sites: Portal de Compras do Governo Federal, para os dados relacionados às compras públicas (indicadores e conteúdo de Editais); Presidência da República, para pesquisas nas legislações vigentes; e Portal do IFRJ, para acesso a informações sobre a instituição.

Os dados coletos a partir da pesquisa dos documentos foram tratados e expostos em figura e tabelas, isto a fim de facilitar o entendimento do leitor.

Os roteiros de questionários combinaram perguntas fechadas e abertas, com o objetivo de identificar a percepção dos servidores solicitantes sobre a inclusão de critérios sustentáveis nos materiais demandados, buscando verificar as principais dificuldades enfrentadas. Os questionários foram aplicados à amostra dos servidores envolvidos no processo de compras que possuem o seguinte perfil: (i) dois anos de efetivo exercício do cargo público; (ii) realização de, ao menos, uma solicitação de material.

Os roteiros possuem 12 questões e foram aplicados no período de 13 a 20 de junho de 2019. O questionário completo foi confeccionado no Google Formulários e encaminhado aos respondentes via e-mail. Dos 32 questionários enviados, obteve-se 30 respostas. 0 universo dos entrevistados é composto por 15 técnicos administrativos e 15 docentes.

As entrevistas foram aplicadas com o intuito de avaliar a visão dos sujeitos sobre as suas experiências, concepções e dificuldades enfrentadas na implantação das compras com critérios sustentáveis. Os sujeitos, todos servidores de carreira do quadro permanente do IFRJ, foram selecionados devido a investidura em função de direção/coordenação e/ou por possuírem atribuições ligadas ao planejamento, supervisão e operacionalização de compras públicas na entidade.

As entrevistas foram aplicadas a seis servidores e ocorreram individualmente no período de 14 de junho a 5 de julho de 2019. Tendo duração média de 25 min, sendo inicialmente gravadas e posteriormente transcritas para análise dos seus conteúdos. 0 roteiro aplicado possui 11 perguntas. 


\section{O IFRJ}

O Instituto Federal de Educação, Ciência e Tecnologia do Rio de Janeiro é uma instituição pautada nos princípios do pluralismo de ideias, da inclusão social, da busca pela excelência e da indissociação do ensino, pesquisa e extensão, entendida como indispensáveis para a construção de uma educação de qualidade. O IFRJ oferece formação em diferentes áreas do saber, aliado ao desenvolvimento de projetos de pesquisa e extensão, ambos voltados à inovação tecnológica e a divulgação do conhecimento (Portal do IFRJ, 2020).

Desde o ano de 2008, após promulgação da Lei no 11.892/2008 (Brasil, 2008), a instituição possui a atual denominação e estrutura, sendo constituído como Autarquia Federal dotada de autonomia pedagógica, administrativa e financeira, organizado na forma multicampi e especializado na oferta de educação profissional e tecnológica em diferentes modalidades de ensino. Atualmente, o IFRJ possui uma Reitoria, na cidade do Rio de Janeiro, e os campi Arraial do Cabo, Belford Roxo, Duque de Caxias, Engenheiro Paulo de Frontin, Mesquita, Nilópolis, Niterói, Paracambi, Pinheiral, Realengo, Resende, Rio de Janeiro, São Gonçalo, São João de Meriti e Volta Redonda, totalizando quinze campi (IFRJ, 2015).

No que se refere à sustentabilidade, a instituição é signatária da Agenda Ambiental na Administração Pública (A3P) e conta com a Pró-reitoria de Desenvolvimento Institucional, Valorização de Pessoas e Sustentabilidade que, dentre outras políticas, supervisiona as ações das comissões de sustentabilidade da reitoria e dos campi.

\section{O Campus Paracambi do IFRJ}

Os campi do IFRJ são unidades descentralizadas de ensino distribuídas nas regiões Metropolitana, Médio Paraíba, Centro-Sul Fluminense e Baixadas Litorâneas do estado do Rio de Janeiro. Eles gozam de autonomia administrativa, financeira e pedagógica, podendo gerir seu orçamento, alocar seus servidores e estabelecer suas diretrizes educacionais conforme a sua real necessidade, assim atendendo melhor às especificidades do local onde está inserido e possibilitando uma gestão mais flexível e dinâmica. Apesar desta elevada autonomia, estes se encontram subordinados diretamente a Reitoria que estabelece as políticas gerais da instituição, além de concentrar e repassar o orçamento devido para cada um dos campi.

Na estrutura administrativa do Campus Paracambi do IFRJ, regulamentada pelo Regimento Geral de 2011, a incumbência da gestão dos recursos orçamentários cabe ao Diretor Geral (investido da função de Ordenador de Despesas), ao Diretor de Administração (atuando como Gestor Financeiro) e a Coordenação do Orçamento e Financeiro (responsável por instrumentalizar as atividades financeiras e orçamentárias). A operacionalização das licitações é atribuída a Coordenação de Compras (CoComp) e a especificação dos materiais, obras e serviços compete aos servidores (técnicos administrativos e professores) investidos na função de solicitante. A abertura e acompanhamento dos processos de aquisição estão a cargo do Setor de Protocolo.

Em dezembro de 2019, o Campus Paracambi do IFRJ contava com 1.005 alunos distribuídos na Licenciatura em Matemática, Bacharel em Engenharia Mecânica e nos cursos Médio Técnico Integrado em Mecânica Industrial e em Eletrotécnica. Para operacionalizar a sua rotina administrativa e executar a sua atividade fim, o campus possuía, na data de referência, um total de 79 professores e 52 técnicos administrativos em educação.

\section{Processos de compras no Campus do IFRJ}

No IFRJ, cabe ao servidor solicitante acessar o CATMAT e pesquisar a descrição do objeto mais adequado ao fim desejado, observando-se o conjunto de características do produto, a unidade de fornecimento e seu código de referência. Importante notar, que 
para uma licitação constar como sustentável no Portal de Compras do Governo Federal, o solicitante deve selecionar no CATMAT os itens cadastrados com critérios de sustentabilidade na sua constituição, pois, caso contrário, a compra não será registrada como sustentável.

Vale destacar que, qualquer servidor pode apontar a necessidade da compra de produtos e da contratação de serviços indispensáveis ao cumprimento das suas atribuições, observado o interesse público. Portanto, independentemente do cargo, setor e atividade que execute no seu cotidiano laboral, este profissional terá a incumbência de detalhar o objeto pretendido e preencher o Termo de Referência de acordo com as previsões legais.

Para determinar o quantitativo e o percentual dos processos de compras com critérios sustentáveis (PCCS) ocorridas no campus, foi necessário enumerar o total de aquisições efetuadas no período estudado. Do somatório, verificou-se os processos que contaram com a adoção da sustentabilidade em seu termo de referência, assim como, utilizaram-se de especificações verdes.

No período de janeiro de 2013 a dezembro de 2019, o campus Paracambi do IFRJ executou um total de 222 processos de compras (Tabela 1) para contratação de diferentes materiais e tipos de serviços. No cumprimento destes processos foram homologados o montante de $\mathrm{R} \$ 17.860 .807,61$ (Tabela 2). Importante observar o baixo índice de aquisições registradas como sustentáveis no Portal de Compras.

Tabela 1. Detalhamento dos processos de compra realizados pelo campus Paracambi do IFRJ.

\begin{tabular}{lccccc}
\hline Período & Processos de compras (total) & Pregão & Dispensa & Inexigibilidade & PCCS \\
\hline $\mathbf{2 0 1 3}$ & 48 & 16 & 7 & 25 & 0 \\
$\mathbf{2 0 1 4}$ & 43 & 11 & 7 & 25 & 1 \\
$\mathbf{2 0 1 5}$ & 46 & 11 & 4 & 31 & 0 \\
$\mathbf{2 0 1 6}$ & 29 & 4 & 12 & 13 & 0 \\
$\mathbf{2 0 1 7}$ & 20 & 1 & 8 & 11 & 0 \\
$\mathbf{2 0 1 8}$ & 16 & 1 & 3 & 12 & 0 \\
$\mathbf{2 0 1 9}$ & 20 & 8 & 5 & 7 & 0 \\
\hline Total & 222 & 52 & 46 & 124 & 1 \\
\hline
\end{tabular}

Fonte: Portal de Compras do Governo Federal.

Tabela 2. Processos de compras e seus valores homologados.

\begin{tabular}{lcccc}
\hline Período & Processos de compras (total) & Valor (total) & PCCS & Valor (PCCS) \\
\hline 2013 & 48 & $\mathrm{R} \$ 2.632 .681,46$ & 0 & - \\
2014 & 43 & $\mathrm{R} \$ 933.702,40$ & 1 & $\mathrm{R} \$ 2.280,00$ \\
2015 & 46 & $\mathrm{R} \$ 6.059 .873,52$ & 0 & - \\
2016 & 29 & $\mathrm{R} \$ 1.228 .011,29$ & 0 & - \\
2017 & 20 & $\mathrm{R} \$ 506.238,65$ & 0 & - \\
2018 & 16 & $\mathrm{R} \$ 738.576,93$ & 0 & - \\
2019 & 20 & $\mathrm{R} \$ 5.761 .723,36$ & 0 & - \\
\hline Total & 222 & $\mathrm{R} \$ 17.860 .807,61$ & 1 & $\mathrm{R} \$ 2.280,00$ \\
\hline
\end{tabular}

Fonte: Portal de Compras do Governo Federal. 
Na Tabela 1, observa-se a composição detalhada dos processos de compras do campus, sendo 52 Pregões (23,42\%), 46 Dispensas de licitação (20,72\%) e 124 Inexigibilidade de licitação $(55,86 \%)$. Os pregões realizados foram do tipo eletrônico destinados a aquisição direta ou por sistema de registro de preços (SRP) de bens e serviços comuns. As dispensas, em sua maioria, foram empregadas para uma aquisição mais ágil de bens e serviços com baixo valor, de acordo com a previsão do art. 24, inciso II, da Lei no 8.666/1993 (Brasil, 1993). As inexigibilidades foram utilizadas, especialmente, para a compra de equipamentos (maquinários e bancadas) e serviços destinados aos laboratórios didáticos, prestados por fornecedores exclusivos, e a contratação de cursos de capacitação de servidores, individualmente ou in company.

O decréscimo no número de pregões realizados é reflexo da adoção, a partir de 2016, de política institucional voltada a realização de compras compartilhadas.

Analisando as Tabelas 1 e 2, no período de janeiro de 2013 a dezembro de 2019 o Campus Paracambi do IFRJ realizou 222 processos de compras, homologando um total de $\mathrm{R} \$ 17.860 .807,61$ e, deste montante, apenas $\mathrm{R} \$ 2.280,00$ foram destinados para a aquisição de bens sustentáveis. A partir destes dados, pode-se inferir que os servidores de Paracambi ainda não estão preparados para operacionalizar as CPS. Assim, explicitando a necessidade de atender de maneira mais efetiva às legislações, que impõem ao poder público, a obrigação de adotar critérios sustentáveis nos produtos, obras e serviços contratados.

O baixo índice de CPS do campus está inserido no contexto nacional (Figura 1). Visto que, a mesma problemática também é assistida nos demais órgãos da Administração Pública Federal, pois, no ano de 2018, os entes do Executivo Federal empregaram o montante de $\mathrm{R} \$ 48.196 .808 .747,06$ em 102.657 processos de compras, deste total apenas 991 com itens sustentáveis, que movimentaram o valor de $\mathrm{R} \$ 131.633 .766,57$, segundo o Portal de Compras do Governo Federal (Brasil, 2020).

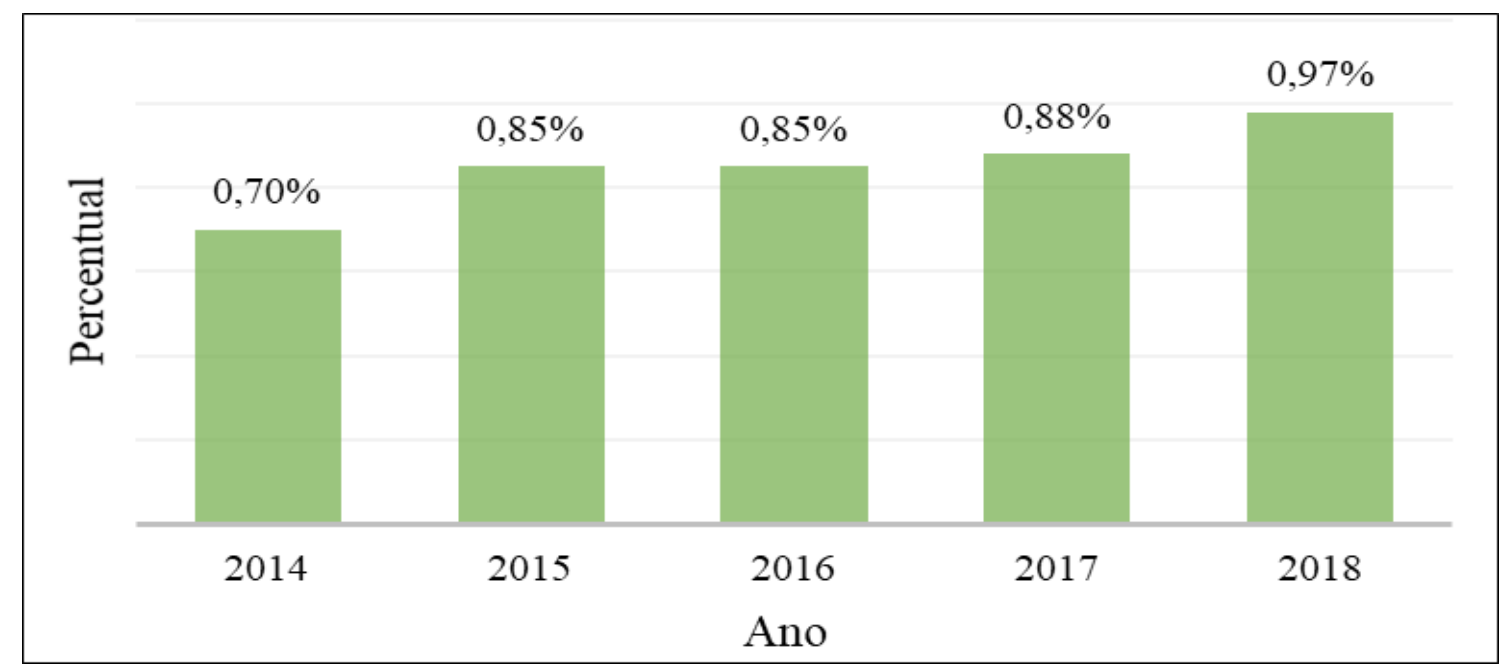

Figura 1. Percentual de PCCS em relação ao total licitado por ano. Fonte: Portal de Compras do Governo Federal.

\section{Análise dos resultados}

Nas pesquisas predominantemente qualitativas, a análise e interpretação dos dados coletados devem ser capazes de captar elementos do discurso e da prática dos 
envolvidos, com isso valorizando o ponto de vista daqueles que realmente vivenciam o problema estudado. Os autores Yin (2001), Vergara (2005) e Bardin (2016) classificam esta etapa como uma das mais complexas do estudo de caso.

\section{Aplicação e análise dos questionários}

As questões do roteiro visam identificar a percepção dos servidores solicitantes, especialmente, sobre a inclusão de critérios sustentáveis nos materiais demandados, buscando perceber as principais dificuldades enfrentadas por estes atores do processo. Os dados coletados foram obtidos a partir dos 30 questionários respondidos e analisados a partir de uma perspectiva interpretativa, pois se buscou uma visão holística do fenômeno estudado, isto aliando as evidências verificadas a outros fatores explícitos e implícitos observados no Campus Paracambi do IFRJ.

Inicialmente, todos os respondentes afirmaram saber o que é sustentabilidade no contexto das compras públicas. Esta informação foi utilizada para a análise das demais respostas.

As questões de 1 a 5 foram elaboradas e organizadas no roteiro de maneira complementar, formando primeiro bloco de perguntas, especialmente, tratando de aspectos subjetivos sobre sustentabilidade e sua aplicabilidade nas compras públicas. A partir das respostas, pode-se observar que, apesar do reconhecimento da importância do tema, a instituição ainda apresenta dificuldades, sobretudo, em fases decisórias do processo e no estímulo à capacitação dos atores envolvidos no processo licitatório. Visto que, poucos servidores alegaram conhecer políticas institucionais de incentivo e apoio às ecoaquisições.

As questões de 6 a 10 foram formuladas e dispostas no roteiro de forma articulada, integrando o segundo bloco de perguntas, todas orientadas a medir aspectos relacionadas a aplicação prática dos conceitos de CPS e o nível de divulgação/existência de ferramentas de suporte aos servidores solicitantes de materiais sustentáveis. A partir das informações coletadas, interpreta-se, especialmente, dificuldades relacionadas a obstáculos na gestão do conhecimento e na aprendizagem organizacional. Dado que a maioria afirmou não ter conhecimento suficiente para fundamentar e especificar os objetos de forma sustentáveis, portanto sinalizando a importância do recebimento de suporte de outros servidores e de materiais específicos.

As duas últimas perguntas do roteiro eram, respectivamente, com múltiplas alternativas e aberta.

Na questão com múltiplas alternativas, das quatro alternativas mais apontadas, três podem ser diretamente atribuídas a problemas envolvendo a falta de capacitação de servidores e a política de compras institucional, pois o desconhecimento da legislação, a cultura organizacional e a falta de material de apoio corroboram esta percepção. Vale destacar que, a baixa oferta no mercado e os preços dos produtos sustentáveis também foram apontados como complicadores para a concretização das CPS, tendo em vista a real necessidade de avanços no segmento verde.

Na última pergunta, os servidores foram provocados a colaborar com a pesquisa, por meio de sugestões para vencer as barreiras encontradas no processo de especificação sustentável. Por se tratar de pergunta aberta, os respondentes puderam se expressar livremente.

Após exame das respostas, todas as contribuições oferecidas estavam relacionadas a cinco tópicos. A Tabela 3 contém as categorias citadas, número de menções e o cerne das respostas. 
Tabela 3. Síntese das respostas da pergunta aberta.

\begin{tabular}{|c|c|c|}
\hline Categoria & Menções & Cerne \\
\hline Capacitação & 21 & Ofertar e estimular a participação de cursos relacionados às CPS; \\
\hline $\begin{array}{l}\text { Divulgação } \\
\text { institucional }\end{array}$ & 8 & $\begin{array}{l}\text { Intensificar a disseminação de práticas, objetivos e informações } \\
\text { sobre sustentabilidade e sua aplicação nas licitações, } \\
\text { especialmente, aquelas desenvolvidas no IFRJ; }\end{array}$ \\
\hline Material de apoio & 8 & Divulgar e elaborar ferramentas práticas de suporte ao solicitante; \\
\hline $\begin{array}{l}\text { Política } \\
\text { organizacional }\end{array}$ & 4 & $\begin{array}{l}\text { Incluir as CPS de maneira efetiva como uma política institucional, } \\
\text { estabelecendo metas e normativas aos gestores; }\end{array}$ \\
\hline $\begin{array}{l}\text { Redesenho do } \\
\text { processo }\end{array}$ & 1 & $\begin{array}{l}\text { Verificar a possibilidade de mapeamento do processo de compra e } \\
\text { posterior redesenho, a fim de otimizar o procedimento licitatório. }\end{array}$ \\
\hline
\end{tabular}

Apesar desta questão ser aberta, observou-se que as respostas apresentadas foram bastante convergentes, pois as categorias divulgação institucional, material de apoio e capacitação, com destaque ao último, são considerados relevantes por elevada parcela do universo dos servidores. Além disso, vale registrar que as respostas dadas ao questionário se conectam de forma coerente, ou seja, existindo uma construção lógica quando examinadas em conjunto.

\section{Aplicação e análise das entrevistas}

As entrevistas semiestruturadas envolveram a participação de 6 indivíduos, todos servidores de carreira do quadro permanente do IFRJ e detentores de funções e/ou atribuições relacionadas ao planejamento, supervisão e operacionalização de compras públicas. Sendo realizadas com o objetivo de avaliar as experiências, perspectivas e dificuldades enfrentadas pelos sujeitos na implantação das compras com critérios sustentáveis no Campus Paracambi do IFRJ e na organização em geral.

Preliminarmente, todos os entrevistados afirmaram saber o que é sustentabilidade no contexto das compras públicas. Esta informação foi utilizada para a análise das demais respostas.

Em geral, observou-se a baixa participação em capacitações relacionadas às CPS, com exceção de um respondente, que afirma ter participado de, ao menos, três cursos. A partir deste cenário, infere-se uma das possíveis causas da pouca ocorrência de compras computadas como sustentáveis. Os entrevistados alegam que, especialmente devido à restrição do orçamento destinado à capacitação, nem todos são contemplados com regularidade. Portanto, também se observa outro aspecto relacionado a baixa qualificação.

Os entrevistados acreditam e reafirmam a importância da inclusão de critérios de sustentabilidade nas licitações realizadas pelo IFRJ. Nas respostas, os elementos mais considerados foram a necessidade da preservação ambiental, a promoção do desenvolvimento sustentável e o papel do Estado como comprador e regulador do mercado. Portanto, verifica-se que todos entendem conceitualmente as funções precípuas da CPS.

As principais barreiras apontadas na difusão das licitações sustentáveis foram relacionadas à cultura organizacional da instituição, como a resistência a mudanças, carência na capacitação dos atores envolvidos nos processos de aquisição, preços praticados pelo mercado e a falta de clareza nas legislações vigentes. Vale destacar que, as respostas apresentadas nas entrevistas estão bastante alinhadas àquelas assistidas, especialmente, nas questões 11 e 12 do questionário aplicado aos servidores solicitantes. Fato, que pode ser interpretado como dificuldades na disseminação do conhecimento e na construção de uma cultura favorável às licitações positivas no IFRJ. 
Sobre a adoção de práticas sustentáveis, os respondentes citaram diferentes procedimentos desenvolvidos na instituição, em especial, aquelas previstas na Agenda Ambiental na Administração Pública (A3P). Logo, nos campi do IFRJ têm-se buscado concretizar atividades relacionadas a racionalização do uso da água e da energia, coleta seletiva, correto tratamento e destinação dos resíduos, compras sustentáveis, dentre outras ações. Mas, ao longo das declarações, alguns entrevistados demonstraram certa hesitação em descrever atividades em execução na organização.

Os entrevistados demonstraram confiança no avanço das CPS no Campus Paracambi do IFRJ e na instituição, pois todos sinalizaram diferentes ações que têm sido planejadas e/ou executadas. Sendo assim, em tese, já no próximo ano corrente o IFRJ poderá assistir uma melhoria na gestão dos processos licitatórios e a implementação de procedimentos orientados a promoção da sustentabilidade nas compras.

Nas respostas, destacam-se dois tópicos para elevar os indicadores das CPS na instituição. 0 primeiro mais assinalado foi a necessidade de capacitar os servidores envolvidos nos processos de compra, seja por meio de cursos in company ou por intermédio de iniciativas internas, como cursos de extensão ministrados pelo próprio pessoal da organização. 0 segundo ponto mais destacado é referente à normatização de procedimentos, entendido como algo importante para estabelecer padrões a serem seguidos por gestores, pregoeiros e solicitantes.

Sobre a possibilidade de criação de guia prático, os entrevistados acreditam ser interessante o desenvolvimento de trabalhos como este, pois desconhecem a existência de ferramentas voltadas a especificação sustentáveis de materiais. Outro ponto positivo destacado, relaciona-se com a verificação daqueles produtos com preços similares àqueles atualmente existentes nos almoxarifados da instituição, tendo em vista que os valores mais elevados dos bens sustentáveis, normalmente, são entendidos como o maior impeditivo de se realizar uma CPS. Também foi ressaltado a facilidade e celeridade que o catálogo pode oferecer, principalmente, aos servidores solicitantes.

A partir do exame das respostas, o método de análise de conteúdo fornece três categorias finais, que sintetizam os significados identificadas no cerne dos discursos estudados. Sendo elas: carência na capacitação, cultura organizacional e desconhecimento sobre materiais de apoio.

\section{Discussão}

Após a alteração e regulamentação da Lei nº 8.666/1993 (Brasil, 1993), respectivamente, pela Lei no 12.349/2010 (Brasil, 2010) e pelo Decreto no 7.746/2012 (Brasil, 2012), o Poder Público foi obrigado a estabelecer critérios e práticas visando a promoção do desenvolvimento nacional sustentável em suas compras. Estas previsões, necessariamente, devem estar contidas nos instrumentos convocatórios e na especificação dos objetos das contratações.

Apesar da previsão legal, do avanço das políticas de incentivo e da crescente diversificação de materiais e serviços oferecidos no mercado, as CPS ainda são incipientes no Brasil - conforme exposto na Figura 1. Nesta perspectiva, a presente publicação buscou oferecer contribuições teóricas e práticas para aumentar a efetividade das licitações positivas, como instrumento capaz de fomentar o desenvolvimento nacional sustentável.

No decorrer da pesquisa, pode-se observar que ainda existem diferentes complicadores que limitam a opção por materiais sustentáveis, apesar dos avanços nas legislações, na cultura de consumo e na oferta de mercado. Dentre os principais identificados, temos o desconhecimento de como proceder para a realização de uma especificação sustentável, a tendência de preços mais elevados, a dificuldade de comprovação da procedência dos componentes dos itens e problemas na avaliação do ciclo de vida dos produtos. 
A abrangência e complexidade do assunto podem ser entendidas como empecilhos para a ocorrência de especificações verdes, pois em parcela dos casos observados, os servidores entrevistados desconheciam os procedimentos necessários para a realização da CPS. Apesar da constante queda dos valores de determinados materiais sustentáveis, em grande parte, estes ainda apresentam preços mais elevados, quando comparados aos similares "comuns".

Aliado ao exposto nos dois parágrafos anteriores, também temos o acúmulo de atividades e funções no cotidiano laboral dos indivíduos estudados, o que influencia na escolha do caminho mais "simples e seguro". Portanto, optando preferencialmente por produtos usualmente ofertados no mercado e por aqueles habitualmente adquiridos pela instituição.

No entanto, no decorrer do estudo dos Editais e Termos de Referência do Campus Paracambi do IFRJ, pode-se verificar a preocupação dos gestores, pregoeiros e solicitantes de incluir a exigência da adoção de critérios e práticas de sustentabilidade nos instrumentos convocatórios divulgados. Logo, o baixo índice de ecoaquisições registradas, também, decorre da seleção incorreta do item cadastrado no CATMAT.

Apesar do esforço da gestão do IFRJ em impulsionar as práticas sustentáveis no cotidiano da reitoria e dos campi, o que vem gradualmente modificando a cultura organizacional e gerando resultados, especialmente, no uso racional dos recursos disponíveis. No tocante as CPS, infere-se a importância de construir guia prático focado nas etapas iniciais de instrução do processo, ou seja, um documento contendo sugestões de especificação sustentável, seleção do código CATMAT, justificativas e amparos legais.

Embora existam estudos, como o de Couto e Ribeiro (2016, p. 341) que apontam "a posição majoritária dos especialistas ao afirmar que já existem informações suficientes, mas que há falta de interesse e capacidade para sua correta utilização", no ambiente pesquisado, observou-se a carência de guias práticos contendo orientações ajustadas a demanda do cotidiano e adequadas aos servidores ocupantes de cargo de direção e coordenação ou àqueles responsáveis pela solicitação de materiais. Posto que, estes podem ou não possuir formação em áreas diretamente ligadas ao exercício da função investida ou da tarefa designada.

Outras pesquisas recentes, como a realizada por Goulart e Pietrafesa (2019), também constataram dificuldades na implementação de práticas sustentáveis efetivas em órgãos do Poder Público. A referida publicação ajuda a corroborar a conclusão deste estudo, pois mesmo sendo realizada em contexto diverso, apresenta resultados igualmente negativos.

\section{Conclusões}

O presente trabalho buscou, a partir da condução de estudo de caso, analisar possível solução para promover o crescimento das aquisições sustentáveis, especialmente, no Campus Paracambi do IFRJ. Considerando os baixos índices de CPS apresentados e os dados coletados nos questionários e entrevistas.

Com base no exposto, infere-se a validade da construção de guia prático específico capaz de estabelecer diálogo entre a teoria e a prática. Com isso, buscando minimizar aspectos internos relacionados a carência na capacitação dos atores envolvidos no processo de aquisição, a cultura organizacional resistente a mudanças e 0 desconhecimento de manuais voltados a licitação sustentável.

Nesta perspectiva, o desenvolvimento de guia prático elaborado com base nas especificidades encontradas no Campus Paracambi do IFRJ poderá constituir ponto de partida para a efetivação das ecoaquisições como prática recorrente neste ambiente. No entanto, vale destacar que as experiências vividas e os conteúdos produzidos também poderão ser replicados nos demais campi do IFRJ e em outras instituições públicas. 
Por último, é oportuno mencionar a necessidade de futuros estudos e do constante fomento das licitações positivas. Dado o dinamismo, a complexidade e a relevância do tema.

\section{Agradecimentos}

Os autores agradecem à Universidade Federal Rural do Rio de Janeiro (UFRRJ) e ao Instituto Federal de Educação, Ciência e Tecnologia do Rio de Janeiro (IFRJ).

\section{Conflitos de interesse}

Os autores declaram não haver conflitos de interesse.

\section{Referências}

Alencastro, M. A. C.; Silva, E. V.; Lopes, A. M. A. Contratações sustentáveis na administração pública brasileira: a experiência do Poder Executivo federal. Revista de Administração

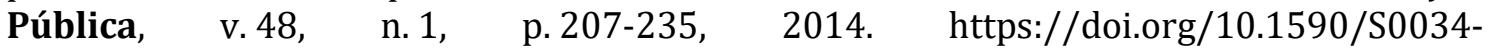
76122014000100009

Bardin, L. Análise de conteúdo. 1. ed. São Paulo: Edições 70, 2016.

Betiol, L. S.; Uehara, T. H. K.; Laloe, F. K.; Appugliese, G. A.; Adeodato, S.; Ramos, L.; Monzoni, M. P. Compra sustentável: a força do consumo público e empresarial para uma economia verde e inclusiva. 1. ed. São Paulo: Editora FGV, 2012.

Biderman, R.; Macedo, L. S. V.; Monzoni, M.; Mazon, R. Guia de compras públicas para a promoção do desenvolvimento sustentável. 2. ed. Rio de Janeiro: FGV, 2008.

Brasil. Decreto no 7.746, de 5 de junho de 2012. Regulamenta o art. 3o da Lei no 8.666 , de 21 de junho de 1993, para estabelecer critérios e práticas para a promoção do desenvolvimento nacional sustentável nas contratações realizadas pela administração pública federal direta, autárquica e fundacional e pelas empresas estatais dependentes, e institui a Comissão Interministerial de Sustentabilidade na Administração Pública - CISAP. (Redação dada pelo Decreto no 9.178, de 2017). Disponível em: <http://www.planalto.gov.br/ccivil_03/_Ato2011-2014/2012/Decreto/D7746.htm>.

Acesso em: 06 jan. 2020.

Brasil. Lei no 8.666, de 21 de junho de 1993. Regulamenta o art. 37, inciso XXI, da Constituição Federal, institui normas para licitações e contratos da Administração Pública e dá outras providências. Disponível em: <http://www.planalto.gov.br/ccivil_03/leis/18666cons.htm>. Acesso em: 06 jan. 2020.

Brasil. Lei no 11.892, de 29 de dezembro de 2008. Institui a Rede Federal de Educação Profissional, Científica e Tecnológica, cria os Institutos Federais de Educação, Ciência e Tecnologia, e dá outras providências. Disponível em: <http://www.planalto.gov.br/ccivil_03/_Ato2007-2010/2008/Lei/L11892.htm>. Acesso em: 06 jan. 2020.

Brasil. Lei no 12.349, de 15 de dezembro de 2010. Altera as Leis nos 8.666 , de 21 de junho de 1993, 8.958, de 20 de dezembro de 1994, e 10.973, de 2 de dezembro de 2004; e revoga o $\S 1^{\mathrm{o}}$ do art. $2^{\mathrm{o}}$ da Lei no 11.273, de 6 de fevereiro de 2006. Disponível em: $<$ http://www.planalto.gov.br/ccivil_03/_Ato2007-2010/2010/Lei/L12349.htm>. Acesso em: 06 jan. 2020. 
Brasil. Portal de Compras do Governo Federal. Manual CATMAT - Catálogo de Material e CATSER: satálogo de serviço. Brasília, 2014.

Brasil. Portal de Compras do Governo Federal. Portal de Compras. 2020. Disponível em: <https://www.comprasgovernamentais.gov.br/>. Acesso em: 06 jan. 2020.

Caldas, E. L.; Nonato, R. S. Compras públicas e promoção do desenvolvimento local. $\begin{array}{llllll}\text { Revista do Serviço Público, v. 64, } & \text { n. } 4, & \text { p. 465-480, } 2013 .\end{array}$ https://doi.org/10.21874/rsp.v64i4.133

Couto, H. L. G.; Ribeiro, F. L. Objetivos e desafios da política de compras públicas sustentáveis no Brasil: a opinião dos especialistas. Revista de Administração Pública, v. 50, n. 2, p. 331-343, 2016. https://doi.org/10.1590/0034-7612146561

Couto, H. L. G.; Coelho, C. Fatores críticos no comportamento do gestor público responsável por compras sustentáveis: diferenças entre consumo individual e organizacional. Revista de Administração Pública, v. 49, n. 2, p. 519-543, 2015. https://doi.org/10.1590/0034-7612113443

Di Pietro, M. S. Z. Direito Administrativo. 29. ed. Rio de Janeiro: Forense, 2016.

Goulart, L. C. R.; Pietrafesa, P. A. Gestão ambiental e a política pública de sustentabilidade do Poder Judiciário de Goiás, Brasil. Revista Brasileira de Gestão Ambiental e Sustentabilidade, v. 6, n. 14, p. 733-748, 2019. https://doi.org/10.21438/rbgas.061408

Laloe, F. K. Arcabouço jurídico para compras públicas sustentáveis no Brasil e o uso de rotulagem e certificações. Washington: PNUMA, 2014. (Projeto Sustainable Public Procurement and Ecollabeling (SPPEL)). Disponível em: <https://www.oneplanetnetwork.org/resource/arcabouco-juridico-para-compraspublicas-sustentaveis-no-brasil-e-o-uso-de-rotulagem-e>. Acesso em: 06 jan. 2020.

Meirelles, H. L. Direito administrativo brasileiro. 42. ed. São Paulo: Malheiros, 2016.

Mello, C. A. B. Curso de Direito Administrativo. 32. ed. São Paulo: Malheiros, 2015.

Oliveira, B.C. S. C. M.; Santos, L. M. L. Compras públicas como política para o desenvolvimento sustentável. Revista de Administração Pública, v. 49, n. 1, p. 189-206, 2015. https://doi.org/10.1590/0034-76121833

Silva, R. C.; Barki, T. V. P. Compras públicas compartilhadas: a prática das licitações sustentáveis. Revista do Serviço Público, v. 63, n. 2, p. 157-175, 2012. https://doi.org/10.21874/rsp.v63i2.93

Vergara, S. C. Métodos de pesquisa em administração. São Paulo: Atlas, 2005.

Yin, R. K. Estudo de caso: planejamento e métodos. 2. ed. Porto Alegre: Bookman, 2001.

Informação da Licença: Este é um artigo Open Access distribuído sob os termos da Licença Creative Commons Attribution, que permite uso irrestrito, distribuição e reprodução em qualquer meio, desde que a obra original seja devidamente citada. 